Pacific Journal of Mathematic 


\title{
ON METRIZABILITY OF COMPLETE MOORE SPACES
}

\author{
G. M. REED
}

\begin{abstract}
This paper is concerned with the relationships between certain 'strong' completeness properties in Moore spaces and with conditions under which Moore spaces satisfying these properties are metrizable.
\end{abstract}

In [3], Heath showed that each regular $T_{2}$-space which admits a strongly complete semi-metric is a complete Moore space. Furthermore, in [6], Heath established that each separable Moore space which admits a strongly complete semi-metric is metrizable. In [10], the author defined strong star-screenability, a property shared by separable spaces and metrizable spaces, and conjectured that separability could be replaced by strong star-screenability in Heath's result. In this paper, the author establishes relationships between different types of completeness in Moore spaces and gives two new metrization theorems for complete Moore spaces. From these results, it follows that each strongly star-screenable Moore space which admits a continuous, strongly complete semi-metric is metrizable.

An admissible semi-metric $d$ for a $T_{2}$-space $S$ is a distance function for $S$ such that (1) if each of $x$ and $y$ is a point of $S$, then $d(x, y)=d(y, x) \geqq 0$, (2) $d(x, y)=0$ if and only if $x=y$, and (3) the topology of $S$ is invariant with respect to $d$. A semi-metric $d$ for the space $S$ is said to be strongly complete provided that if $M_{1}, M_{2}, \cdots$ is a decreasing sequence of closed sets such that for each $i, M_{i} \subset$ $\left\{y \in S \mid d\left(x_{i}, y\right)<1 / i\right\}$ for some $x_{i} \in S$, then $\cap M_{i} \neq \varnothing$. A space which admits a strongly complete semi-metric is said to be strongly complete. A development for a space $S$ is a sequence $G_{1}, G_{2}, \cdots$ of open coverings of $S$ such that, for each $n, G_{n+1}$ is a subcollection of $G_{n}$, and for each point $p$ and each open set $D$ containing $p$, there is an integer $n$ such that every element of $G_{n}$ containing $p$ is a subset of $D$. A development $G_{1}, G_{2}, \cdots$ for the space $S$ is said to be complete (sequentially complete) provided that if $M_{1}, M_{2}, \ldots$ is a monotonic sequence of closed sets such that for each $i, M_{i} \subset g_{i}$ for some $g_{i} \in G_{i}$ $\left(M_{i} \subset \operatorname{st}\left(x_{i}, G_{i}\right)\right.$ for some $\left.x_{i} \in S\right)$, then $\bigcap M_{i} \neq \varnothing$. A regular space having a development is a Moore space [1]. A Moore space having a complete (sequentially complete) development is said to be complete (sequentially complete). The property of sequential completeness is due to Traylor in [11]. Although each of strong completeness and sequential completeness is stronger than completeness in Moore spaces ([8] and [11]), for pointwise paracompact Moore spaces, all three are equivalent ([4] and [11]). A space $S$ is said to be star-screenable 
(strongly star-screenable) if and only if, for each open covering $G$ of $S$, there exists a $\sigma$-pairwise disjoint ( $\sigma$-discrete) open covering $H$ of $S$ which refines $\{$ st $(x, G) \mid x \in S\}$.

Lemma 1. Each sequentially complete Moore space $S$ is strongly complete.

Proof. Let $G_{1}, G_{2}, \cdots$ denote a sequentially complete development for $S$. Denote by $d$ the "natural semi-metric" for $S$ determined by this development, i.e., $d(x, y)=0$ if $x=y$ and $d(x, y)=1 / n$, where $n$ is the first positive integer such that no element of $G_{n}$ contains both $x$ and $y$, if $x \neq y$. It follows that if $M_{1}, M_{2}, \cdots$ is a monotonic decreasing sequence of closed sets such that for each $i$, there exists $x_{i} \in S$ such that $M_{i} \subset\left\{y \in S \mid d\left(x_{i}, y\right)<1 / i\right\}$, then for each $i, M_{i} \subset$ st $\left(x_{i}, G_{i}\right)$ and $\cap M_{i} \neq \varnothing$. Thus $S$ is strongly complete.

Lemma 2. Each Moore space $S$ which admits a continuous, strongly complete semi-metric is sequentially complete.

Proof. Let $d$ denote a continuous, strongly complete semi-metric for $S$. For each $p \in S$ and each positive integer $n$, let $g_{n}(p)$ denote an open set containing $p$ such that if $x \in g_{n}(p)$ and $y \in g_{n}(p)$, then $d(x, y)<1 / n$. Now, for each $n$, let $H_{n}=\left\{g_{n}(p) \mid p \in S\right\}$. It follows immediately that $G_{1}, G_{2}, \cdots$, where for each $i, G_{i}=\bigcup_{j=i}^{\infty} H_{j}$, is a development for $S$. It is also a sequentially complete development. For suppose that $M_{1}, M_{2}, \cdots$ is a monotonic decreasing sequence of closed sets such that for each $i$, there exists a point $p_{i}$ such that $M_{i} \subset \operatorname{st}\left(p_{i}, G_{i}\right)$, then for each $i, M_{i} \subset\left\{x \in S \mid d\left(x, p_{i}\right)<1 / i\right\}$ and $\bigcap M_{i} \neq$ $\varnothing$. Thus, $S$ is sequentially complete.

THEOREM 1. Each normal, sequentially complete, star-screenable Moore space $S$ is metrizable.

Proof. Denote by $G_{1}, G_{2}, \cdots$ a sequentially complete development for $S$. Each normal star-screenable Moore space is strongly starscreenable [10]. Thus for each $i$, let $H_{i}=\bigcup_{j} H_{i j}$ denote an open cover of $S$ which refines $\left\{\right.$ st $\left(x, G_{i}\right) \mid x \in S$ \} such that $H_{i j}$ is discrete for each $j$. Since $S$ is normal and each open set in $S$ is the union of countably many closed sets, for each $i$ and $j$, let $H_{i j}^{*}=\bigcup_{k} H_{i j k}$ such that for each $k, H_{i j k}$ is open in $S$ and CL $\left(H_{i j k}\right) \subset H_{i j}^{*}$. For each $i, j$, and $k$, let $F_{i j k}=\left\{H_{i j k} \cap h \mid h \in H_{i j}\right\}$ and note that if $f \in F_{i j k}$, then CL $(f) \subset \operatorname{st}\left(x, G_{i}\right)$ for some $x \in S$. Now, for each $n$, let $F_{n}$ denote a $\sigma$-discrete collection of open sets covering $S$ such that if $f \in F_{n}$, then $\mathrm{CL}(f) \subset \operatorname{st}\left(x, G_{n}\right)$ for some $x \in S$. Let $B_{1}=F_{1}$ and for each $i>1$, 
let $B_{i}$ denote the $\sigma$-discrete collection $\left\{f \cap b \mid f \in F_{i}\right.$ and $\left.b \in B_{i-1}\right\}$. Finally, let $B=\bigcup B_{i}$ and note that $B$ is a $\sigma$-discrete collection of open sets covering $S$. However, $B$ is also a basis for $S$. For let $p \in S$ and let $D$ be an open set containing $p$. Then by the construction of $B$ there exists a sequence of open sets $g_{1}(p), g_{2}(p), \cdots$ such that for each $i, p \in g_{i}(p), g_{i}(p) \in B_{i}, g_{i+1}(p) \subset g_{i}(p)$, and $\operatorname{CL}\left(g_{i}(p)\right) \subset \operatorname{st}\left(x_{i}, G_{i}\right)$ for some $x_{i} \in S$. Suppose that for each $i, g_{i}(p) \cap(S-D) \neq \varnothing$. Then $\left(\mathrm{CL}\left(g_{1}(p)\right)-D\right)$, (CL $\left.\left(g_{2}(p)\right)-D\right), \cdots$ is a monotonic decreasing sequence of closed sets such that for each $i,\left(\mathrm{CL}\left(g_{i}(p)\right)-D\right) \subset \operatorname{st}\left(x_{i}, G_{i}\right)$ for some $x_{i} \in S$. Since $G_{1}, G_{2}, \cdots$ is a sequentially complete development for $S, \cap\left(\mathrm{CL}\left(g_{i}(p)\right)-D\right) \neq \varnothing$. Thus, let $x \in \bigcap\left(\mathrm{CL}\left(g_{i}(p)\right)-D\right)$ and note that for each $i$, there exist intersecting elements $g_{1}$ and $g_{2}$ of $G_{i}$ which contain $x$ and $p$ respectively. But this contradicts the fact that $G_{1}, G_{2}, \cdots$ is a development for $S$. Thus, for some $n$, $g_{n}(p) \subset D$ and $B$ is a $\sigma$-discrete basis for $S$. Therefore, $S$ is strongly screenable, hence metrizable [1].

Heath in [7] defines a Moore space $S$ with the three link property to be one with a development $G_{1}, G_{2}, \cdots$ having the three link property, i.e., for each two points $p$ and $q$ of $S$, there exists an $n$ such that if $g_{1}, g_{2}$, and $g_{3}$ are elements of $G_{n}, g_{1}$ contains $p$ and intersects $g_{2}$, and $g_{2}$ intersects $g_{3}$, then $g_{3}$ does not contain $q$. Zenor has shown in [12] that $A$ Moore space has the three link property if and only if it has a regular $G_{\tilde{o}}$-diagonal.

THEOREM 2. Each sequentially complete, strongly star-screenable Moore space $S$ with the three link property is metrizable.

Proof. Without loss of generality, let $G_{1}, G_{2}, \cdots$ denote a sequentially complete development for $S$ with the three link property. Now, by a construction similar to the one used in the proof of Theorem 1 , let $B=\bigcup B_{i}$ denote a $\sigma$-discrete open covering of $S$ such that for each $i$, if $b \in B_{i}$, then $b \subset$ st $\left(x, G_{i}\right)$ for some $x \in S$. (Note that without normality, we cannot require $\mathrm{CL}(b) \subset \mathrm{st}\left(x, G_{i}\right)$.) However, $B$ still forms a basis for $S$. For suppose that $p \in S$ and $D$ is an open set containing $p$. Then there exists a sequence of open sets $g_{1}(p), g_{2}(p), \cdots$ such that for each $i, p \in g_{i}(p), g_{i}(p) \in B_{i}, g_{i+1}(p) \subset g_{i}(p)$, and $g_{i}(p) \subset$ st $\left(x_{i}, G_{i}\right)$ for some $x_{i} \in S$. Suppose that for each $i, g_{i}(p) \cap(S-D) \neq$ $\varnothing$. Thus, for each $i$, let $p_{i} \in g_{i}(p) \cap(S-D)$. Consider $\left\{p_{1}, p_{2}, \cdots\right\}$. Suppose this set has no limit point. Then for each $i, M_{i}=\left\{p_{i}, p_{i+1}, \cdots\right\}$ is a closed set such that $M_{i} \subset \operatorname{st}\left(x_{i}, G_{i}\right)$ for some $x_{i} \in S$. And since $G_{1}, G_{2}, \cdots$ is a sequentially complete development for $S, \cap M_{i} \neq \varnothing$. But if $\cap M_{i} \neq \varnothing$, as in the proof of Theorem 2, we contradict the fact that $G_{1}, G_{2}, \cdots$ is a development for $S$. However, if $x$ is a limit point of $\left\{p_{1}, p_{2}, \cdots\right\}$, then for each $i$, there exists an element $g_{1}$ of $G_{i}$ 
which contains both $x$ and $p_{j}$ for some $j>i$. But $p_{j} \in g_{j}(p)$ and $g_{j}(p) \subset \operatorname{st}\left(x_{j}, G_{j}\right)$ for some $x_{j} \in S$. Thus, there exist intersecting elements $g_{2}$ and $g_{3}$ of $G_{j}$, hence of $G_{i}$, which contain $p$ and $p_{j}$ respectively. Therefore, for each $i$, there exist elements $g_{1}, g_{2}$, and $g_{3}$ of $G_{i}$ such that $g_{1}$ contains $x$ and intersects $g_{2}, g_{2}$ intersects $g_{3}$, and $p \in g_{3}$. But this contradicts the fact that $G_{1}, G_{2}, \ldots$ has the three link property. Thus, for some $n, g_{n}(p) \subset D$ and it follows that $B$ is a $\sigma$-discrete basis for $S$. Again, by [1], $S$ is metrizable.

THEOREM 3. Each strongly star-screenable Moore space $S$ which admits a continuous, strongly complete semi-metric is metrizable.

Proof. By Lemma 2, $S$ is sequentially complete. And from ([2], Theorem 8) it follows that $S$ has the three link property. Thus, by Theorem $2, S$ is metrizable.

The next two theorems show that Theorem 3 is a reasonable partial answer to question (5) in [10].

THEOREM 4. There exists a strongly star-screenable Moore space which admits a continuous semi-metric that is not metrizable.

Proof. In [2], Cook gave an example of a separable, nonmetrizable Moore space which admits a continuous semi-metric. Since each separable space is strongly star-screenable, that example has the desired properties.

THEOREM 5. There exists a Moore space $S$ which admits a continuous, strongly complete semi-metric which is not metrizable.

Proof. Consider the following Moore space $S$ given by Heath in [5]. The points of $S$ are all points of the plane on or above the $x$ axis. For each positive integer $n$, define $H_{n}$ as follows: (1) for $p$ above the $x$-axis, $\{p\} \in H_{n}$; (2) for each rational number $r$ on the $x$ axis, $\{(r, y) \mid o \leqq y \leqq 1 / n\} \in H_{n}$; (3) for each irrational number $x$ on the $x$-axis, $\{(t, y) \mid t=x+y, o \leqq y \leqq 1 / n\} \in H_{n}$. Then, $\bigcup H_{n}$ forms a basis for $S$ and the sequence $G_{1}, G_{2}, \cdots$, where for each $i, G_{i}=\bigcup_{j=i}^{\infty} H_{j}$, is a development for $S$. It is easily seen that the "natural semi-metric" for $S$ with respect to this development has the required properties.

\section{REFERENCES}

1. R. H. Bing, Metrization of topological spaces, Canad. J. Math., 3 (1951), 175-186.

2. H. Cook, Cartesian products and continuous semi-metrics, Proc. of the Arizona State Univ. Top. Conf., (1967), 58-62. 
3. R. W. Heath, Arcwise connectedness in semi-metric spaces, Pacific J. Math., 12 (1963), 1301-1319.

4. — A nonpointwise paracompact Moore space with a point countable base, Notices Amer. Math. Soc., 10 (1963), 649-650.

5. - Screenability, pointwise paracompactness, and metrization of Moore spaces, Canad. J. Math., 16 (1964), 763-770.

6. —- Separability and $\aleph_{1}$-compactness, Coll. Math., 12 (1964), 11-14.

7. — Metrizability, compactness, and paracompactness in Moore spaces, Notices Amer. Math. Soc., 10 (1963), 105.

8. L. F. McAuley, A relation between perfect separability, completeness, and normality in semi-metric spaces, Pacific J. Math., 6 (1956), 315-326.

9. R. L. Moore, Foundations of Point Set Theory, Amer. Math. Soc. Coll. Publ. 13, Revised Edition, Providence, R.I., 1962.

10. G. M. Reed, On screenability and metrizability of Moore spaces, Canad. J. Math., 23 (1971), 1087-1092.

11. D. R. Traylor, Completeness in developable spaces, preprint.

12. P. Zenor, On spaces with regular Gs-diagonals, Pacific J. Math., 40 (1972), 759-763.

Received January 28, 1972 and in revised form July 31, 1973.

OHIO UNIVERSITY 



\section{PACIFIC JOURNAL OF MATHEMATICS}

\section{EDITORS}

RICHARD ARENS (Managing Editor)

University of California

Los Angeles, California 90024

\section{R. A. Beaumont \\ University of Washington \\ Seattle, Washington 98105}

\section{J. DugundjI*}

Department of Mathematics University of Southern California Los Angeles, California 90007

D. Gilbarg and J. Milgram

Stanford University

Stanford, California 94305

\section{ASSOCIATE EDITORS}
E. F. BeCKenBaCH
B. H. NeumanN
F. WOLF
K. YoSHIDA

\section{SUPPORTING INSTITUTIONS}

\author{
UNIVERSITY OF BRITISH COLUMBIA \\ CALIFORNIA INSTITUTE OF TECHNOLOGY \\ UNIVERSITY OF CALIFORNIA \\ MONTANA STATE UNIVERSITY \\ UNIVERSITY OF NEVADA \\ NEW MEXICO STATE UNIVERSITY \\ OREGON STATE UNIVERSITY \\ UNIVERSITY OF OREGON \\ OSAKA UNIVERSITY
}

\author{
UNIVERSITY OF SOUTHERN CALIFORNIA \\ STANFORD UNIVERSITY \\ UNIVERSITY OF TOKYO \\ UNIVERSITY OF UTAH \\ WASHINGTON STATE UNIVERSITY \\ UNIVERSITY OF WASHINGTON

$* * *$
$*$
AMERICAN MATHEMATICAL SOCIETY
NAVAL WEAPONS CENTER

The Supporting Institutions listed above contribute to the cost of publication of this Journal, but they are not owners or publishers and have no responsibility for its content or policies.

Mathematical papers intended for publication in the Pacific Journal of Mathematics should be in typed form or offset-reproduced, (not dittoed), double spaced with large margins. Underline Greek letters in red, German in green, and script in blue. The first paragraph or two must be capable of being used separately as a synopsis of the entire paper. Items of the bibliography should not be cited there unless absolutely necessary, in which case they must be identified by author and Journal, rather than by item number. Manuscripts, in duplicate if possible, may be sent to any one of the four editors. Please classify according to the scheme of Math. Rev. Index to Vol. 39. All other communications to the editors should be addressed to the managing editor, or Elaine Barth, University of California, Los Angeles, California, 90024.

100 reprints are provided free for each article, only if page charges have been substantially paid. Additional copies may be obtained at cost in multiples of 50 .

The Pacific Journal of Mathematics is issued monthly as of January 1966. Regular subscription rate: $\$ 60.00$ a year (6 Vols., 12 issues). Special rate: $\$ 30.00$ a year to individual members of supporting institutions.

Subscriptions, orders for back numbers, and changes of address should be sent to Pacific Journal of Mathematics, 103 Highland Boulevard, Berkeley, California, 94708.

PUBLISHED BY PACIFIC JOURNAL OF MATHEMATICS, A NON-PROFIT CORPORATION

Printed at Kokusai Bunken Insatsusha (International Academic Printing Co., Ltd.), 270, 3-chome Totsuka-cho, Shinjuku-ku, Tokyo 160, Japan

* C. R. DePrima California Institute of Technology, Pasadena, CA 91109, will replace J. Dugundji until August 1974. 


\section{Pacific Journal of Mathematics}

Vol. 50, No. $2 \quad$ October, 1974

Mustafa Agah Akcoglu, John Philip Huneke and Hermann Rost, A counter example to the Blum Hanson theorem in general spaces .............

Huzihiro Araki, Some properties of modular conjugation operator of von

Neumann algebras and a non-commutative Radon-Nikodym theorem

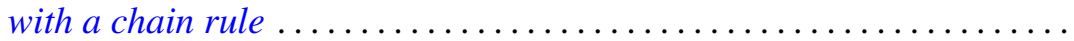

E. F. Beckenbach, Fook H. Eng and Richard Edward Tafel, Global properties of rational and logarithmico-rational minimal surfaces .....

David W. Boyd, A new class of infinite sphere packings ............. 383

K. G. Choo, Whitehead Groups of twisted free associative algebras ........

Charles Kam-Tai Chui and Milton N. Parnes, Limit sets of power series

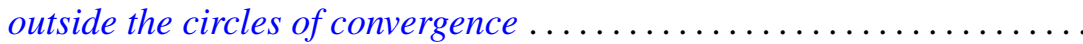

Allan Clark and John Harwood Ewing, The realization of polynomial

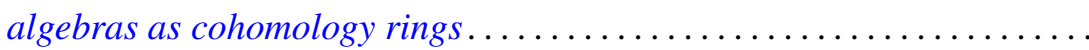

Dennis Garbanati, Classes of circulants over the p-adic and rational

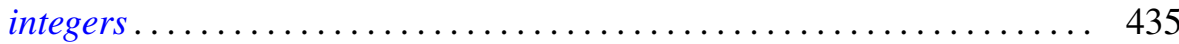

Arjun K. Gupta, On a "square" functional equation ................... 449

David James Hallenbeck and Thomas Harold MacGregor, Subordination and extreme-point theory ............................. 455

Douglas Harris, The local compactness of $v X \ldots \ldots . . . . . . . . . . . .4469$

William Emery Haver, Monotone mappings of a two-disk onto itself which fix the disk's boundary can be canonically approximated by homeomorphisms .................................. 477

Norman Peter Herzberg, On a problem of Hurwitz .................. 485

Chin-Shui Hsu, A class of Abelian groups closed under direct limits and subgroups formation ............................... 495

Bjarni Jónsson and Thomas Paul Whaley, Congruence relations and multiplicity types of algebras.....................

Lowell Duane Loveland, Vertically countable spheres and their wild sets.

Nimrod Megiddo, Kernels of compound games with simple components ....

Russell L. Merris, An identity for matrix functions ........ . .

E. O. Milton, Fourier transforms of odd and even tempered distributions ...

Dix Hayes Pettey, One-one-mappings onto locally connected generalized continua

Mark Bernard Ramras, Orders with finite global dimension

Doron Ravdin, Various types of local homogeneity. .

George Michael Reed, On metrizability of complete Moore spaces ...

Charles Small, Normal bases for quadratic extensions ..

Philip C. Tonne, Polynomials and Hausdorff matrices.... . . 